\title{
Effect of sodium fluoride in chlorhexidine mouthwashes on force decay and permanent deformation of orthodontic elastomeric chain
}

\author{
Erliera Sufarnap ${ }^{1 *}$, Kholidina Imanda Harahap ${ }^{2}$, Terry ${ }^{1}$ \\ ${ }^{1}$ Department of Orthodontics, Faculty of Dentistry Universitas Sumatera Utara, Indonesia \\ ${ }^{2}$ Department of Dental Material, Faculty of Dentistry Universitas Sumatera Utara, Indonesia
}

\begin{abstract}
Introduction: Orthodontic elastomeric chain is polyurethane elastomer that is widely used among orthodontists due to its functions. Chlorhexidine (CHX) and sodium fluoride $(\mathrm{NaF})$ are listed in mouthwash composition which could affect the mechanical properties of the elastomeric chain. This study was aimed to analyze the effect of sodium fluoride in chlorhexidine mouthwashes on force decay and permanent deformation of orthodontic elastomeric chains. Methods: This research is an experimental analytic laboratory with pretest-posttest control group design. 150 samples of orthodontic chains were divided into three groups. Group 1: artificial saliva (control group); Group 2: 0,1\% chlorhexidine gluconate solution (CHX); Group 3: 0,1\% chlorhexidine digluconate with sodium fluoride solution (CHX-NaF). The orthodontic elastomeric chain was stretched and maintained at a standardized distance equivalent to a force of $300 \mathrm{~g}$. The measurement of force decay and permanent deformation were performed with digital force gauge and digital caliper $(0.01 \mathrm{~mm})$ at intervals of the first, seventh, fourteenth, twentyfirst, and twenty-eighth days, respectively. Results: The force decay and permanent deformation of the elastomeric chain compared among three groups (control, $\mathrm{CHX}$ mouthwash and $\mathrm{CHX}+\mathrm{NaF}$ mouthwash) showed did not have any significantly different ( $p$-value $>0,05)$ at the first, seventh, fourteenth, twentyfirst, and twenty-eighth days, respectively. Conclusion: Sodium fluoride in chlorhexidine mouthwash showing no difference among saliva, $\mathrm{CHX}$ mouthwash and $\mathrm{CHX}+\mathrm{NaF}$ mouthwash on force decay and permanent deformation of elastomeric chain.
\end{abstract}

Keywords: sodium fluoride; force decay; permanent deformation; elastomeric chain; chlorhexidine mouthwash.

p-ISSN: 1979-0201; e-ISSN: 2549-6212; Available from: http://jurnal.unpad.ac.id/pjd/article/view/26370

DOI: 10.24198/pid.vol33no1.26370

Submission: Feb 18, 2020; Accepted: Mar 30, 2021; Published online: Mar 31, 2021

"Corresponding author: Erliera Sufarnap, Department of Orthodontics, Faculty of Dentistry Universitas Sumatera Utara, Indonesia. 2, Jalan Universitas, Medan City, North Sumatra, Indonesia, 20155. Phone: +62819827733; Email: erliera@usu. ac.id 


\section{INTRODUCTION}

The orthodontics elastomeric chain is polyurethane elastomer that widely used among orthodontists. ${ }^{1,2}$ It is a long chain with an interconnected hole, and available in various colors. ${ }^{3}$ Due to its elastic ability, orthodontics elastomeric chain can return to its original dimensions when subjected to deformation forces. ${ }^{2,4}$ Orthodontics elastomeric chain are used in any movement that requires pulling, such as tooth derotation, canine and incisor retraction, mild space closure, midline correction, mesial displacement in the posterior quadrants, and traction of impacted teeth. ${ }^{5,6}$ According to the length of filament, orthodontics elastomeric chain divided into closed chain, short link chain, medium link chain and long link chain. ${ }^{7}$

Orthodontics elastomeric chains have many clinical advantages. Specifically, they are economic, easy to use and can be adjusted to the patient's needs, does not require patient's cooperation, good biocompatibility, able to reduce the risk of intraoral trauma and provide light, continuous, as well as powerful assistance in appropriate tooth movement. ${ }^{3,8,9}$ However, the disadvantage is that the force produced is irreversible so it must be replaced after some time. ${ }^{2,3}$

Deformation, force decay and relaxation behaviors of orthodontics elastomeric chain are also dependent on environmental factors like teeth movement, temperature changes, environmental $\mathrm{pH}$, mouthwashes, salivary enzymes and mastication forces. ${ }^{10}$ Studies have shown that the elastics tested in a humid medium underwent greater degradation than those tested in a dry medium. ${ }^{11}$ The rapid decrease in forces of orthodontic elastomeric chains causes insufficient tooth movement resulted in increased appointments for activating the appliance. ${ }^{10}$ Studies have shown a $28-50 \%$ loss of initial force as early as $8 \mathrm{~h}$ after chain insertion into the oral cavity. After $24 \mathrm{~h}$, the rate of initial force loss decreased significantly but is still continued in the following 2 to 4 weeks afterward. ${ }^{8}$

Poor oral hygiene is a major concern during orthodontic treatment. Orthodontic treatment with fixed appliance alters the oral environment, there is an increased accumulation of plaque around the bands and brackets. ${ }^{12}$ Dentists recommend using mouthwashes during orthodontic treatment to promote oral hygiene and decrease caries lesions. It is shown that using chemical agents along with tooth brushing and flossing is better than mechanical control alone, in the way that both plaque and gingival inflammation could be decrease. ${ }^{10}$ Among the antimicrobial agents for oral use, chlorhexidine and sodium fluoride are commonly used in mouthwash ingredients. ${ }^{12}$

Chlorhexidine (CHX) is a bis-biguanide agent with antibacterial properties, having a special affinity for the oral structures and presents a high level of effectiveness. Sodium fluoride (NaF) has an advantage which could promote re-mineralization and make the enamel resistant to acid attack. Chlorhexidine causes long term disadvantages such as tooth color change and taste alteration. While sodium fluoride as an ionized fluoride on the tooth surface causes calcium fluoride sedimentation on the enamel surface..$^{10,13}$ Fluoride mouthwashes are avoided in children less than 6 years of age, as the risk of ingestion is high. ${ }^{13}$

Previous study has been carried out by Omidkhoda et al. by comparing the types of mouthwashes containing sodium fluoride, chlorhexidine and persica which have an influence force decay of orthodontics elastomeric chain. However, the main ingredient of the mouthwash was different from one another which is not contain any sodium fluoride in chlorhexidine concentration in its mouthwash. ${ }^{14}$ The same study was also carried out by Al-Attar et al, by comparing the types of chlorhexidine mouthwashes based on different concentration. ${ }^{12}$ Nevertheless, there is lack of information about the effect of sodium fluoride which were available in chlorhexidine mouthwashes on force decay and permanent deformation of orthodontics elastomeric chain. The purpose of this study was to analyze the effect of sodium fluoride in chlorhexidine mouthwashes on force decay and permanent deformation of orthodontics elastomeric chain.

\section{METHODS}

This research was an experimental laboratory analytic research in vitro with pretest-posttest control group design. The research was conducted at the Orthodontic Clinic of Dental Hospital of Universitas Sumatera Utara. Statistical analysis 
used parametric technique one-way ANOVA and non-parametric technique Kruskal-Wallis test.

\section{Samples}

One-hundred and fifty samples of orthodontics elastomeric chains (American Orthodontics $\AA$ ) with four links were used. All samples were short type elastomeric chains with transparent color. The orthodontic elastomeric chains were randomly divided into 3 experimental groups $(n=50)$, for three different mouthwashes solution: Group 1 (Control) - immersed in artificial saliva; Group 2 immersed in Minosep ${ }^{\circledR}$ mouthwash (contain $0,1 \%$ chlorhexidine gluconate will be abbreviate to $\mathrm{CHX)}$ for 30 second; Group 3 immersed in Kin $®$ mouthwash (contain $0,12 \%$ chlorhexidine digluconate with $0,05 \%$ sodium fluoride will be abbreviate to $\mathrm{CHX}+\mathrm{NaF}$ ) for 30 second. Each group will then divide into five subgroups $(n=10)$ according to five times of day observation last, i.e. $1,7,14,21,28$ days.

The tools used in this research was a square wood board measuring $10 \times 5 \times 1 \mathrm{~cm}$ provided as many as 15 pieces, this board received ten aligned marks spaced $17 \mathrm{~mm}$ apart, facing each other on one line, digital force gauge (Shahe $10 \mathrm{~N}$ ), digital caliper with 0.01 accuracy (Mitutoyo $\circledast 150 \mathrm{~mm}$ ), and stopwatch.

\section{Preparation phase}

$\mathrm{CHX}$ (Minosep $\AA), \mathrm{CHX}+\mathrm{NaF}(\mathrm{Kin} \otimes)$, were poured respectively into $300 \mathrm{ml}$ immersion baths; and $\mathrm{CHX}+\mathrm{NaF}$ mouthwash was diluted by adding distilled water to equalize $\mathrm{CHX}$ concentration to $0,1 \%$. Each orthodontic elastomeric chain $(150$ sample) was cut with four links distance for each sample. The initial length of a short elastomeric chain with four links distance. The baseline force controlled equivalent to $300 \mathrm{~g}$ force, and mounted on each wood board with a pin. The first elastomeric chain lumen tip was placed on a wood broad string and the last lumen tip was hooked onto the hook arm of the digital force gauge. Continuous stretching was performed until force equivalent to $300 \mathrm{~g}$ force or the determined distance of about $13,96 \pm 0.17 \mathrm{~mm}$ stretched (Figure 1).

\section{Mouthwash immersion phase}

Experimental of group 1 (Control group) was immersed in artificial saliva, Group 2 was immersed into $0,1 \% \mathrm{CHX}$ (Minosep ${ }^{\circledR}$ ) mouthwash, group 3 was immersed into diluted $\mathrm{CHX}+\mathrm{NaF}$ $(\mathrm{Kin} \otimes)$ mouthwash with final concentration of sodium fluoride $0.0417 \%$ and $0.1 \%$ chlorhexidine (Figure 2).

Both group 2 and 3 have the same concentration of $0.1 \%$ chlorhexidine digluconate. Immersion in mouthwash was done twice each day every 12 hours. The time's length of immersion in each mouthwash was 30 seconds, measured using a stopwatch. After immersion, samples were washed with purified water for 1 minute for complete removal of the mouthwash residues and then stayed immersed in artificial saliva. After the immersion stage, each group was placed in a container and stored in room temperature.

\section{Measurement phase}

Measurement of force decay and permanent deformation were done on each group with digital force gauge (Sanhe, China) and digital caliper (Mitutoyo, Japan). The measurement method of permanent deformation was from the first tip of elastomeric chain lumen which kept on a wood board string and the last lumen tip was removed from the pin, the extended elastomeric chain flattened on the board then measured with a digital caliper eat the other end.

The measurement method of force decay was also the same, but the other elastomeric chain was hooked onto the hook arm of the digital force gauge. Continuous stretching was performed until the elastomeric chain had an equivalent length to the permanent deformation which was measured, then the force decay could be determined. Orthodontics elastomeric chains were measured for their force decay and permanent deformation at time intervals of 1 day, 7 days, 14 days, 21 days and 28 days after immersion.

\section{Statistic Analysis}

Data were studied using Shapiro-Wilk statistical test to assess normal distribution. Then, oneway ANOVA were compared for force decay and Kruskal-Wallis were compared for permanent deformation (elongated). Analysis was continued to General Linear Model-Repeated Measures with Bonferroni Post Hoc to compare each immersion's media. 


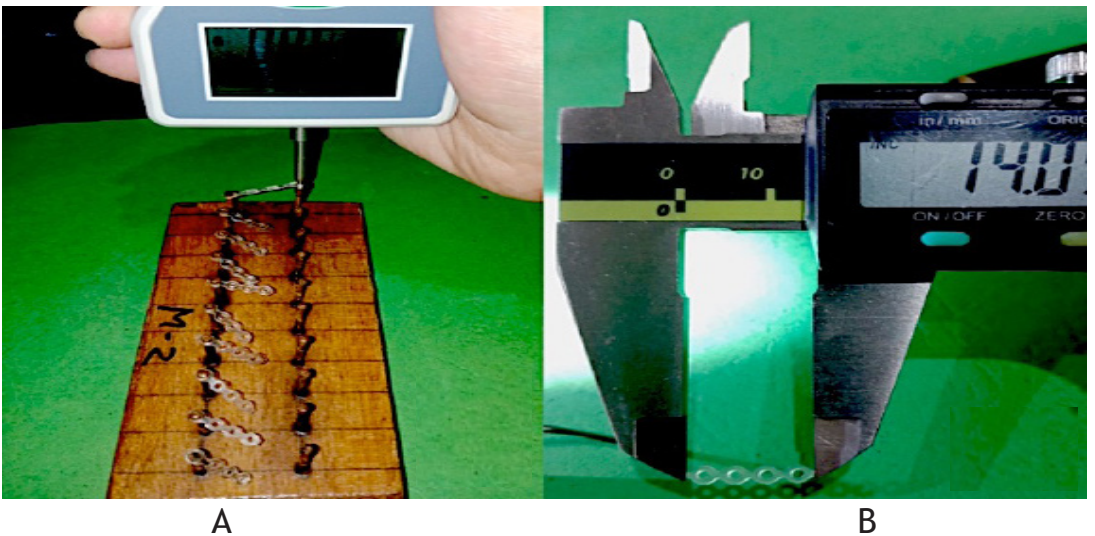

Figure 1. Baseline: A. Elastomeric force; B. Elastomeric length

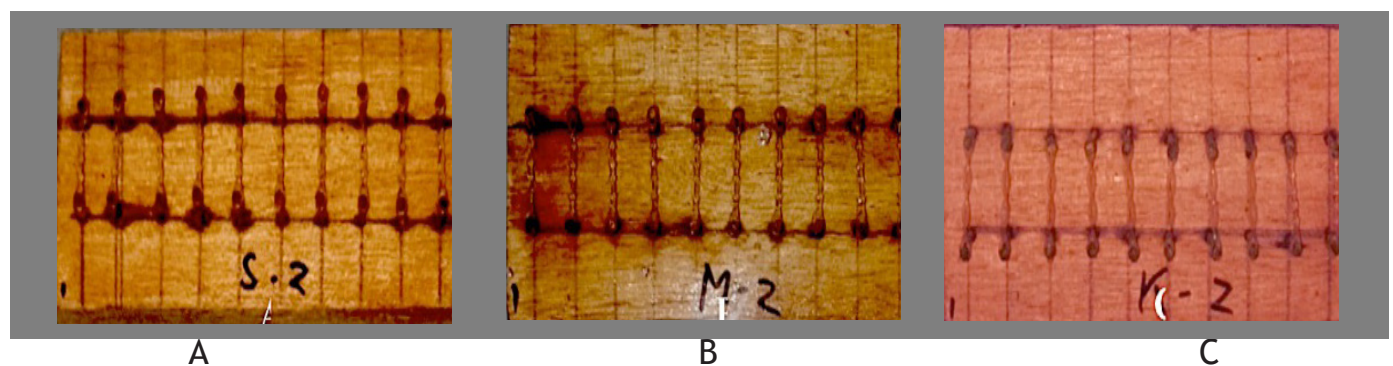

Figure 2. Immersion medium: A. Artificial saliva; B. Chlorhexidine (Minosep®); C. Chlorhexidone + NaF (Kin®)

\section{RESULTS}

In this study, the elastomeric chains in all three groups demonstrated force decay and permanent deformation. The force level of force decay in the elastomeric chains from each group were presented in Table 1. According to the result, the

\begin{tabular}{|c|c|c|c|c|}
\hline \multirow{2}{*}{ Time } & \multirow{2}{*}{ Solution } & \multicolumn{2}{|l|}{ Mean } & \multirow{2}{*}{ P-value* } \\
\hline & & Gram & $\%$ & \\
\hline \multirow{3}{*}{ Day 1} & Saliva & $239.50 \pm 6.10$ & 79.83 & \multirow{3}{*}{0.098} \\
\hline & $\mathrm{CHX}$ & $232.50 \pm 6.80$ & 77.50 & \\
\hline & $\mathrm{CHX}+\mathrm{NaF}$ & $237.50 \pm 8.38$ & 79.17 & \\
\hline \multirow{3}{*}{ Day 7} & Saliva & $215.30 \pm 3.68$ & 71.77 & \multirow{3}{*}{0.087} \\
\hline & $\mathrm{CHX}$ & $211.50 \pm 4.38$ & 70.50 & \\
\hline & $\mathrm{CHX}+\mathrm{NaF}$ & $213.80 \pm 2.90$ & 71.27 & \\
\hline \multirow{3}{*}{ Day 14} & Saliva & $203.80 \pm 7.44$ & 67.93 & \multirow{3}{*}{0.097} \\
\hline & $\mathrm{CHX}$ & $195.30 \pm 10.79$ & 65.10 & \\
\hline & $\mathrm{CHX}+\mathrm{NaF}$ & $199.50 \pm 6.38$ & 66.50 & \\
\hline \multirow{3}{*}{ Day 21} & Saliva & $178.10 \pm 5.41$ & 59.37 & \multirow{3}{*}{0.070} \\
\hline & $\mathrm{CHX}$ & $171.00 \pm 9.33$ & 57.00 & \\
\hline & $\mathrm{CHX}+\mathrm{NaF}$ & $176.10 \pm 4.48$ & 58.70 & \\
\hline \multirow{3}{*}{ Day 28} & Saliva & $169.30 \pm 5.21$ & 56.43 & \multirow{3}{*}{0.080} \\
\hline & $\mathrm{CHX}$ & $163.00 \pm 8.21$ & 54.33 & \\
\hline & $\mathrm{CHX}+\mathrm{NaF}$ & $166.80 \pm 3.77$ & 55.60 & \\
\hline
\end{tabular}

highest force decay from day 1 until day 28 was at group $2(0,1 \% \mathrm{CHX}$ (Minosep $®))$, from $77.5 \%$ to 54.33\%; followed by group 3 (CHX with $\mathrm{NaF}$ (Kin $\circledast)$ ) from $79.17 \%$ to $55.60 \%$; and group 1 as a control group (artificial saliva) $79.83 \%$ to $56.43 \%$. it was not seen statistically difference among those three groups for each time measurement.

Table 2. Average elastomeric chain permanent deformation (elongated) in different solutions at different times

\begin{tabular}{|c|c|c|c|c|c|c|}
\hline \multirow{2}{*}{ Time } & \multirow{2}{*}{ Solution } & \multicolumn{2}{|c|}{ Mean } & \multirow{2}{*}{ Min } & \multirow{2}{*}{ Max } & \multirow{2}{*}{ P-value* } \\
\hline & & $\mathrm{Mm}$ & $\%$ & & & \\
\hline \multirow{3}{*}{$\begin{array}{c}\text { Day } \\
1\end{array}$} & Saliva & 15.67 & 12.25 & 15.24 & 16.17 & \multirow{3}{*}{0.372} \\
\hline & $\mathrm{CHX}$ & 15.77 & 12.97 & 15.54 & 16.05 & \\
\hline & $\mathrm{CHX}+\mathrm{NaF}$ & 15.63 & 11.96 & 15.12 & 15.98 & \\
\hline \multirow{3}{*}{$\begin{array}{c}\text { Day } \\
7\end{array}$} & Saliva & 16.42 & 17.62 & 16.04 & 16.72 & \multirow{3}{*}{0.765} \\
\hline & $\mathrm{CHX}$ & 16.43 & 17.69 & 15.97 & 16.74 & \\
\hline & $\mathrm{CHX}+\mathrm{NaF}$ & 16.50 & 18.19 & 16.20 & 16.83 & \\
\hline \multirow{3}{*}{$\begin{array}{c}\text { Day } \\
4\end{array}$} & Saliva & 16.43 & 17.69 & 16.04 & 17.01 & \multirow{3}{*}{0.100} \\
\hline & $\mathrm{CHX}$ & 16.75 & 19.99 & 16.35 & 17.14 & \\
\hline & $\mathrm{CHX}+\mathrm{NaF}$ & 16.54 & 18.48 & 15.91 & 17.06 & \\
\hline \multirow{3}{*}{$\begin{array}{c}\text { Day } \\
14\end{array}$} & Saliva & 17.01 & 21.85 & 16.36 & 17.48 & \multirow{3}{*}{0.103} \\
\hline & $\mathrm{CHX}$ & 17.30 & 23.93 & 16.14 & 17.94 & \\
\hline & $\mathrm{CHX}+\mathrm{NaF}$ & 16.94 & 21.35 & 16.30 & 17.52 & \\
\hline \multirow{3}{*}{$\begin{array}{c}\text { Day } \\
28\end{array}$} & Saliva & 17.11 & 22.56 & 16.54 & 17.48 & \multirow{3}{*}{0.082} \\
\hline & $\mathrm{CHX}$ & 17.52 & 25.50 & 16.88 & 17.89 & \\
\hline & $\mathrm{CHX}+\mathrm{NaF}$ & 17.33 & 24.14 & 16.75 & 17.69 & \\
\hline
\end{tabular}

${ }^{*}$ Kruskal-Wallis test results 


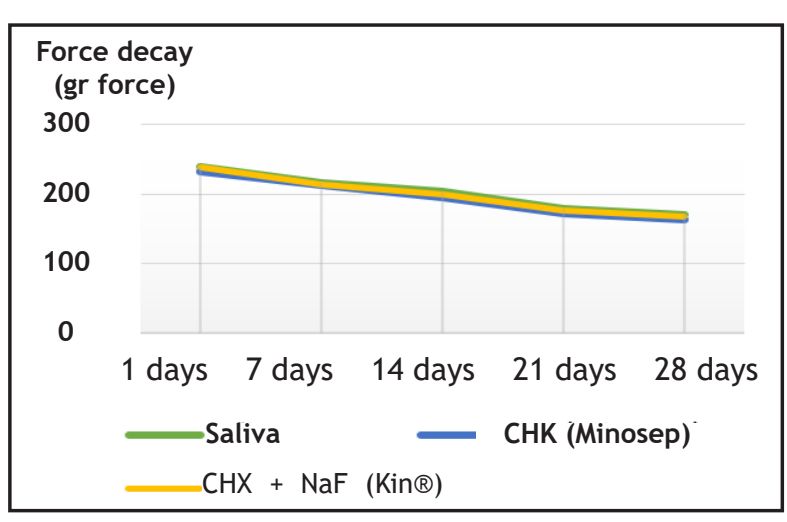

A

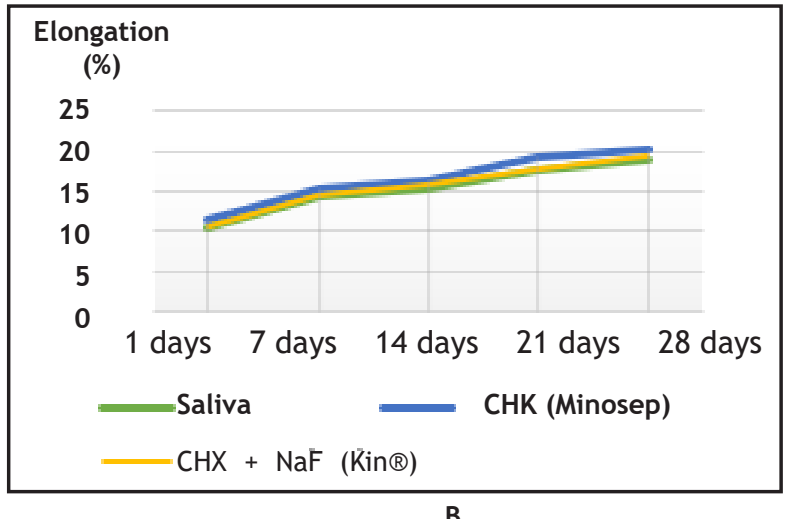

B

Figure 3.A. The difference of force decay between immersion media; B. The difference of permanent deformation (elongated) between immersion media

Table 2 shows permanent deformation (elongated) of the elastomeric chain in different solutions at different times. The highest deformation from day 1 until day 28 was at group 2 (0,1\% CHX (Minosep $®))$, from $12.97 \%$ to $25.50 \%$; followed by group 3 (CHX with $\mathrm{NaF}$ (Kin $\circledast)$ ) from $11.96 \%$ to $24.14 \%$; and the last was a control group (artificial saliva) from 12.25\% to $22.56 \%$. At this table neither was seen any statistically difference between three groups for each time of measurement. From table 1 and 2 showed no significantly found at each time point of measurement. Continuing the post hoc analysis for multiple comparison between variables could not be performed.

\section{DISCUSSION}

Orthodontic elastomeric chains are made up of polyurethane elastomers, which are composed of several repeated subunits called monomers. ${ }^{1}$ Orthodontic elastomeric chains have an ability to return to its original dimensions when subjected to deformation forces. ${ }^{4}$ The applied force makes the molecules of polymer uncoiled; at first, the activated chain is stretched but as time passes, the molecules slip on each other, which results in force decay and permanent deformation. ${ }^{10}$ Environmental factors for our study was controlled to $\mathrm{CHX}$ concentration of immersion solution, humidity of the environment, stayed in room temperature, force applied, no color to the elastomeric chain, because any of differences to environmental such like water, temperature, $\mathrm{pH}$ and time also cause a force decay in orthodontic elastomeric chain. ${ }^{9}$
In this study, the elastomeric chain which was immersed in $0,1 \% \mathrm{CHX}$ has the highest force decay than the elastomeric chain which was immersed in $\mathrm{CHX}+\mathrm{NaF}$ and artificial saliva. Which was in agreement with the results of Omidkhoda et al. study the effect of different mouthwashes on force decay of elastomeric chain were evaluated and at the end of study, showing that mouthwash containing fluoride has a lower force decay than mouthwash without fluoride. ${ }^{14}$ This is because the $\mathrm{CHX}$ immersed solution had the lowest $\mathrm{pH}$ of 4.5 among the other immersion media that has a $\mathrm{pH}$ 6.4 for $\mathrm{CHX}+\mathrm{NaF}$ and for artificial saliva has a $\mathrm{pH}$ of 7.7. Chlorhexidine digluconate has a slightly acidic $\mathrm{pH}$ that varies from 5.5 to 6.0 , with the ability to donate protons. ${ }^{15}$ It can be explained by Clemitson, that elastomer which has an acidic $\mathrm{pH}$ below $<5.4$ or $\mathrm{pH}$ above $>8.0$, the polyurethane material within the elastomeric will be easily hydrolysed. ${ }^{16}$ Acidic condition of $\mathrm{CHX}$ was give more negative effect than it's ingredients itself. Pithon et al.'s study mentioned that the effect of different concentration of chlorhexidine $(0,12 \%$ and $0,2 \%)$ on force decay of elastomeric chain were found no significant difference. ${ }^{17}$ However, to eliminate probable effect of different concentration of the chlorhexidine on force decay, chlorhexidine in this study was controlled into $0.1 \%$ by adding $50 \mathrm{ml}$ of distilled water to dilute Kin ${ }^{\circledR}$ mouthwash.

Also in our study, Group 3 Chlorhexidine with sodium fluoride had less force decay than group 2 with Chlorhexidine only, but we found no statistically difference in this study. This study had an agreement with the results of Al-Attar et al. and Omidkhoda et al., that the effect of different mouthwashes on force decay of elastomeric chain 
showed that mouthwash containing fluoride has a lower force decay than mouthwash without fluoride. ${ }^{12,14}$ Sodium fluoride works to promote remineralization and make the enamel resistant to acid attack. Sodium fluoride is a basic inorganic salt formed by the reaction of weak acids (HF) and strong bases $(\mathrm{NaOH}) .^{13}$

In this study, neither had a significant difference of force decay between the immersion medium $(p>0,05)$ for each time measurement. This is supported by another study by Losito et al. who studied effect of immersion in disinfection solution on force decay of elastomeric chain and at the end of study showing that the disinfection with chlorhexidine and peracetic acid did not affect the degradation of elastomeric chains that used in this study. ${ }^{2}$ This may occur because of time immersion in mouthwash, which were 2 times a day for 30 seconds correspond to patient's daily using of mouthwash. After immersion to mouthwash, the elastomeric chain is also rinsed by purified water which resulted the acidity being removed by a water solution, moreover, the samples then immersed for a longer time in an artificial saliva which corresponded to human mouth. ${ }^{17}$

All elastomeric modules will undergo permanent deformation when subjected to sufficient load. The range was influenced by the rate and loading duration, and the preliminary force was controlled before immersion by the environmental conditions. ${ }^{18}$

Since the study was done under static conditions in vitro, the performance of the elastomeric chain could not simulate the degradation seen in-vivo. Further study is needed controlling the $\mathrm{pH}$ and temperature of the sample while examining the effects of various sodium fluoride concentrations on force decay and permanent deformation. This would allow us a better understanding of the physical properties of orthodontic elastomeric chains. In addition, it is also recommended to use different brands of orthodontic elastomeric chains. This would help to determine whether the results of this study are comparable to what might be seen on a larger scale among different manufacturers. Therefore, although the present findings are a useful guide to the anticipated clinical behavior of the orthodontics elastomeric chain, the observed clinical behavior may differ.
Finally, it is important for the orthodontist to understand the behavior of the materials to achieve appropriate clinical outcomes. Clinically, orthodontics elastomeric chain is replaced at 3-4 week intervals as the result of force decay and permanent deformation. Orthodontists also need to know that a pH that tends to be acidic can cause hydrolysis to the material of the elastomeric, which influences permanent deformation and force decay in orthodontics elastomeric chains.

\section{CONCLUSION}

Sodium fluoride in chlorhexidine mouthwash showed no significant difference among saliva, $\mathrm{CHX}$ mouthwash and $\mathrm{CHX}+\mathrm{NaF}$ mouthwash on force decay and permanent deformation of the elastomeric chain.

\section{ACKNOWLEDGEMENT}

The studies presented in this paper were carried out at the Department of Orthodontic, Faculty of Dentistry on 2019, and continues under the TALENTA's funding batched 2020 from our Research Institution of Universitas Sumatera Utara No.80 / UN5.2.3.1 / PPM / SPP-TALENTA USU/2020 .

\section{REFERENCES}

1. Suprayugo M, Eriwati YK, Santosa AS. Effect of $\mathrm{pH}$ of soft drinks on force decay in orthodontic power chains. J Phys Conf Ser. 2018;1073(6):062016. DOI: 10.1088/17426596/1073/6/062016

2. Losito KAB, Lucato $A S$, Tubel CAM, Correa CAB, dos Santos JCB. Force decay in orthodontic elastomeric chains after immersion in disinfection solutions. Braz J Oral Sci. 2014; 13(4): 266-9. DOI: 10.1590/1677-3225v13n4a05

3. Sulaiman TH, Eriwati YK, Indrani DJ. Effect of temperature on tensile force of orthodontics power chain in artificial saliva solution. J Phys Conf Ser. 2018;1073(6):062006. DOI: 10.1088/1742-6596/1073/6/062006

4. Braga E, Souza G, Barretto P, Ferraz C, Pithon M. Experimental evaluation of strength degradation of orthodontic chain elastics immersed in hot beverages. J Indian Orthod Soc. 2019;53(4):244-8. DOI: 
$10.1177 / 0301574219867540$

5. Masoud Al, Tsay TP, BeGole E, Bedran-Russo AK. Force decay evaluation of thermoplastic and thermoset elastomeric chains: A mechanical design comparison. Angle Orthod. 2014;84(6):1026-33. DOI: 10.2319/010814-28.1

6. Halimi A, Benyahia H, Doukkali A, Azeroual MF, Zaoui F. A systematic review of force decay in orthodontic elastomeric power chains. Int Orthod. 2012;10(3):223-40. DOI: 10.1016/j. ortho.2012.06.013

7. Kharbanda OP. Orthodontics: Diagnosis of and Management of Malocclusion and Dentofacial Deformities. $3^{\text {rd }}$ ed. New Delhi: Elsevier India; 2019.

8. Kardach H, Biedziak B, OlszewskaA, GolusińskaKardach E, Sokalski J. The mechanical strength of orthodontic elastomeric memory chains and plastic chains: An in vitro study. Adv Clin Exp Med. 2017;26(3):373-8. DOI: 10.17219/ acem/61957

9. Cheng HC, Chen MS, Peng BY, Lin WT, Shen YK, Wang YH. Surface treatment on physical properties and biocompatibility of orthodontic power chains. Biomed Res Int. 2017;2017:1-9. DOI: $10.1155 / 2017 / 6343724$

10. Sadeghian S, Heydari G, Shirvani A, Sadeghian $R$. The effect of sodium fluoride and listerine mouthwashes on the force decay of orthodontic elastomeric chains. J Res Med Dent Sci. 2017; 5(5):115-22. DOI: $10.24896 / j$ rmds. 20175518

11. Quenzer JP, Lucato AS, Vedovello SAS, Valdrighi HC, Vedovello Filho M. Influence of elastic chain in the degradation of orthodontic forces - In vitro study. Rev Odontol UNESP. 2015;44(6):320-5. DOI: 10.1590/1807-

\subsection{5}

12. Rafeeq RA, Taha SS, Saleem Al, Al-Attar $A M$. The effect of mouth wash containing chlorhexidine on force degradation of colored elastomeric chains. Int J Sci Res. 2015;6:8928. DOI: $10.21275 /$ ART20172936

13. Shanbhag T, Nayak V, Shenoy S. Pharmacology for Nurses. $2^{\text {nd }}$ ed. New Delhi: Elsevier India; 2016.

14. Omidkhoda $M$, Rashed $R$, Kodarahmi $N$. Evaluation of the effects of three different mouthwashes on the force decay of orthodontic chains. Dent Res J (Isfahan). 2015;12(4):34852. DOI: $10.4103 / 1735-3327.161453$

15. Marion JJC, Pavan K, Arruda MEBF, Nakashima $\mathrm{L}$, de Morais CAH. Chlorhexidine and its applications in endodontics: A literature review. Dent Press Endod. 2013;3(3):36-54.

16. Clemitson IR. Castable Polyurethane Elastomers. $2^{\text {nd }}$ ed. Hoboken: CRC Press; 2015.

17. Pithon MM, Santana DA, Sousa KH, Farias IMAO. Does chlorhexidine in different formulations interfere with the force of orthodontic elastics? Angle Orthod. 2013;83(2):313-8. DOI: $10.2319 / 061312-493.1$

18. de Macêdo EDOD, Collares FM, Leitune VCB, Samuel SMW, Fortes CBB. Pigment effect on the long term elasticity of elastomeric ligatures. Dental Press J Orthod. 2012;17(3):1-6. DOI: 10.1590/s2176-94512012000300009

19. Santana W, Thahar B, Mardiati E, Salim J. The effect of alcohol-containing mouthwash and alcohol-free mouthwash towards the power chains force decay. Padjadjaran J Dent. 2017;29(3):196-203. DOI: 10.24198/pjd. vol29no3.14476 